\title{
Adenoid Cystic Carcinoma of the Lacrimal Gland in a 45 Years Old Male: Case Report and Review of Literature
}

\author{
Khan $\mathrm{AH}^{1}$, Ahmed $\mathrm{N}^{2}$, Shalike $\mathrm{N}^{3}$, Matin $\mathrm{ABMA}^{4}$, Amin $\mathrm{FAA}^{5}$, Barua $\mathrm{S}^{6}$, Kamal $\mathrm{M}^{7}$
}

Conflict of interest: There is no conflict of interest relevant to this paper to disclose.

Funding Agency: Was not funded by any institute or any group.

Contribution of Authors: Khan $\mathrm{AH}$ was Principal investigator, Ahmed N help for protocol preparation, Shalike $\mathrm{N}$, Matin ABMA, Amin FAA, Barua S help for data collection and Kamal $\mathrm{M}$ help for editorial formatting.

Copyright: @2019 Bang. JNS published by BSNS. This article is published under the creative commons CC-BY-NC license.

This license permits use distribution (https://creativecommons.orgf/ licences/by-nc/4-0/) reproduction in any medium, provided the original work is properly cited, and is not used for commercial purposes.

Received: 03 February, 2019 Accepted: 17 February, 2019

\begin{abstract}
: treatment options with reference to the relevant literatures.

$\begin{array}{ll}\text { Abbreviation } \\ \text { ACC } & \text { Adenoid Cystic Carcinoma } \\ \text { AJCC } & \text { American Joint Committee on Cancer } \\ \text { CT } & \text { Computed Tomography } \\ \text { MRI } & \text { Magnetic Resonance Imaging } \\ \text { POD } & \text { Post-operative Day } \\ \text { T1WI } & \text { T1 Weighted Image } \\ T 2 W I & \text { T2 Weighted Image }\end{array}$
\end{abstract}

Adenoid cystic carcinoma $(A C C)$ is a rare malignant tumor that can manifests as proptosis in adult population. They account for $1.6 \%$ of all orbital tumors. Despite their rarity, they are the second most frequent epithelial neoplasms occurring in the lacrimal gland after pleomorphic adenomas. This kind of tumors are commonly occur in the salivary glands but can metastasize to lung, breast, brain and sinuses in hematogenous route. We describe a patient who presented with protrusion of right eyeball, developing over 8 years with history of intermittent watery discharge for 4 years. His magnetic resonance imaging showed a retrobulbarextraconal soft tissue lesion around the lacrimal fossa with invasion and erosion of the adjacent bone. The patient underwent right sided orbito-pterional craniotomy and gross total removal of tumor. Pathologic analysis showed neoplastic cells in a predominantly cribriform pattern with features of perineural invasion and diagnosed as a case adenoid cystic carcinoma of the lacrimal gland. We review the incidence, clinical features, radiographic and histopathologic features of these rare, aggressive malignancies along with current

Keywords: Adenoid cystic carcinoma, lacrimal gland, orbital tumor.

Bang. J Neurosurgery 2019; 9(1): 49-53

\section{Introduction:}

Adenoid cystic carcinomas of the lacrimal gland are rare, but most common malignant tumor of lacrimal gland origin with an estimated incidence of 0.073 per
100,000 individuals annually ${ }^{1}$. Patients may present with asymmetric facial pain or swelling, proptosis,ptosis, diplopia, visual disturbance in the form of dimness of vision and/or double vision ${ }^{2,3}$.

1. Professor Akhlaque Hossain Khan, Professor, Department of Neurosurgery, Bangabandhu Sheikh Mujib Medical University, Dhaka, Bangladesh.

2. Dr. Nazmin Ahmed, MS Neurosurgery Resident, Department of Neurosurgery, Bangabandhu Sheikh Mujib Medical University, Dhaka, Bangladesh.

3. Dr. Narendra Shalike, MS Neurosurgery Resident, Department of Neurosurgery, Bangabandhu Sheikh Mujib Medical University, Dhaka, Bangladesh.

4. Dr. Abul Bashar Md. Abdul Matin, Associate Professor, Department of Surgery, Sheikh Sayera Khatun Medical College, Gopalgonj, Bangladesh.

5. Dr. Firoj Ahmed Al-Amin, MS Neurosurgery Resident, Department of Neurosurgery, Bangabandhu Sheikh Mujib Medical University, Dhaka, Bangladesh.

6. Dr. Sudip Barua, MS Neurosurgery Resident, Department of Neurosurgery, National Institute of Neurosciences and Hospital, Dhaka, Bangladesh.

7. Prof. Mohammed Kamal, Professor, Department of Pathology, Bangabandhu Sheikh Mujib Medical University, Dhaka, Bangladesh. Address of Correspondence: Prof. Akhlaque Hossain Khan, Professor, Department of Neurosurgery, Bangabandhu Sheikh Mujib Medical University, Dhaka, Bangladesh.

Email: fahimshahriyer1@googlemail.com akhlaque63@neuro@yahoo.com, Mobile: +880-1711471153 
Magnetic resonance imaging (MRI) of brain and orbit is the preferred imaging modality for both the diagnosis and surgical planning. Adenoid cystic carcinomas are aggressive tumors having poor prognosis. Surgery is the primary modality of treatment followed by adjuvant chemo-radiation.

In our case report,we describe a patient who presented with right sided extra-axial painless non pulsatile proptosis with MRI findings of an irregular well circumscribed extra-conalsoft tissue mass in the lacrimal fossa with globe deformation and surrounding bone erosion. Gross total removal of the tumor was achieved. Histopathology report confirmed the diagnosis of adenoid cystic carcinoma of the lacrimal gland. We review the incidence, clinical features, radiographic and histopathological features of these rare, aggressive malignancies along with current treatment options with reference to the relevant literatures.

\section{Case Report}

A 45-years-old man with no past medical history presented with gradual protrusion of his right eyeball for 8 years with intermittent excessive watering from the same eye for 4 years. He denied localized pain or numbness around his eye for preceding 7.5 years. But for last 6 months, he noticed orbital pain and a small mass at the upper eyelid. On examination, the patient had extra-axialproptosis of the right eyeball with mild congestion (Figure 1). There was a palpable, mildly tender soft tissue mass, having attachment with orbital rim. On examination, visual acuity was $6 / 18$ in right eye and $6 / 6$ in the left eye;visual fields of both eyes were intact. Ocular movements were full in all gazes. His pupils were equally round \& reactive, and

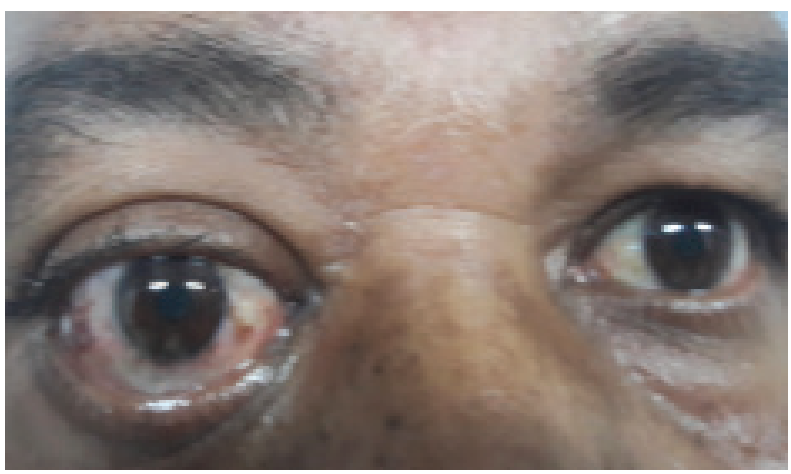

Fig.-1: Patient presented with right sided extra-axial proptosis.

the fundoscopic examination was unremarkable. $\mathrm{He}$ had no palpable lymph nodes.

Computed tomography (CT) scan of the orbit showed anirregular, soft tissue mass in the area of lacrimal fossa, having calcification and erosion of orbital plate of frontal bone (Figure 2:A, B) . MRI of brain and orbit revealedanheterogeneously enhancing, $\mathrm{T} 1$ iso- to hypo-intense and T2-hyperintense irregular soft tissue mass which was retrobulbar, extra-conal,associated with forward displacement of right eyeball, invasion of right lateral rectus muscle, and erosion of the adjacent orbital walls. The mass had extradural extension towards the anterior cranial fossa.lt had also a positivedural tail sign (Figure 3: A, B).

The patient underwent right orbito-pterional craniotomy and gross total removal of tumor (Figure 4: A, B, C). Per-operatively the tumor was irregular, firm, greyish red in color with moderate vascularity. There was no clear demarcation between tumor and normal orbital content. Peri-orbita was eroded and tumor had extension into anterior cranial fossa. Based on the

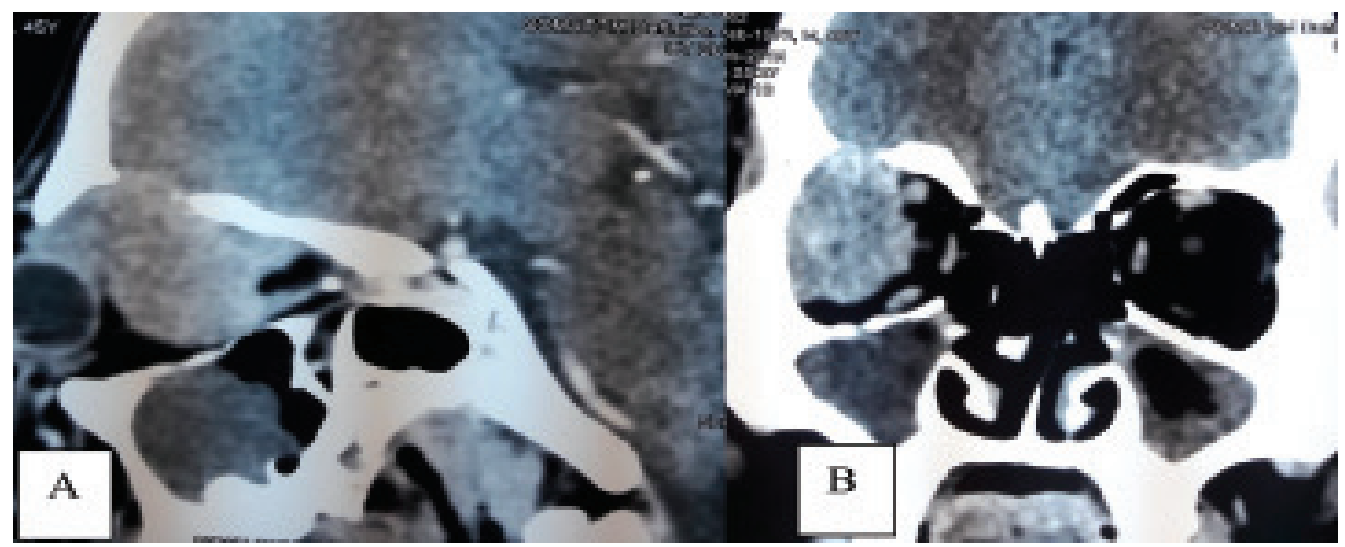

Fig.-2: CT scan of brain with contrast- sagittal $(A)$ and coronal $(B)$ sections showing a retrobulbar extra-conal lesion, causing displacement of optic nerve and erosion of orbital plate of frontal bone. 


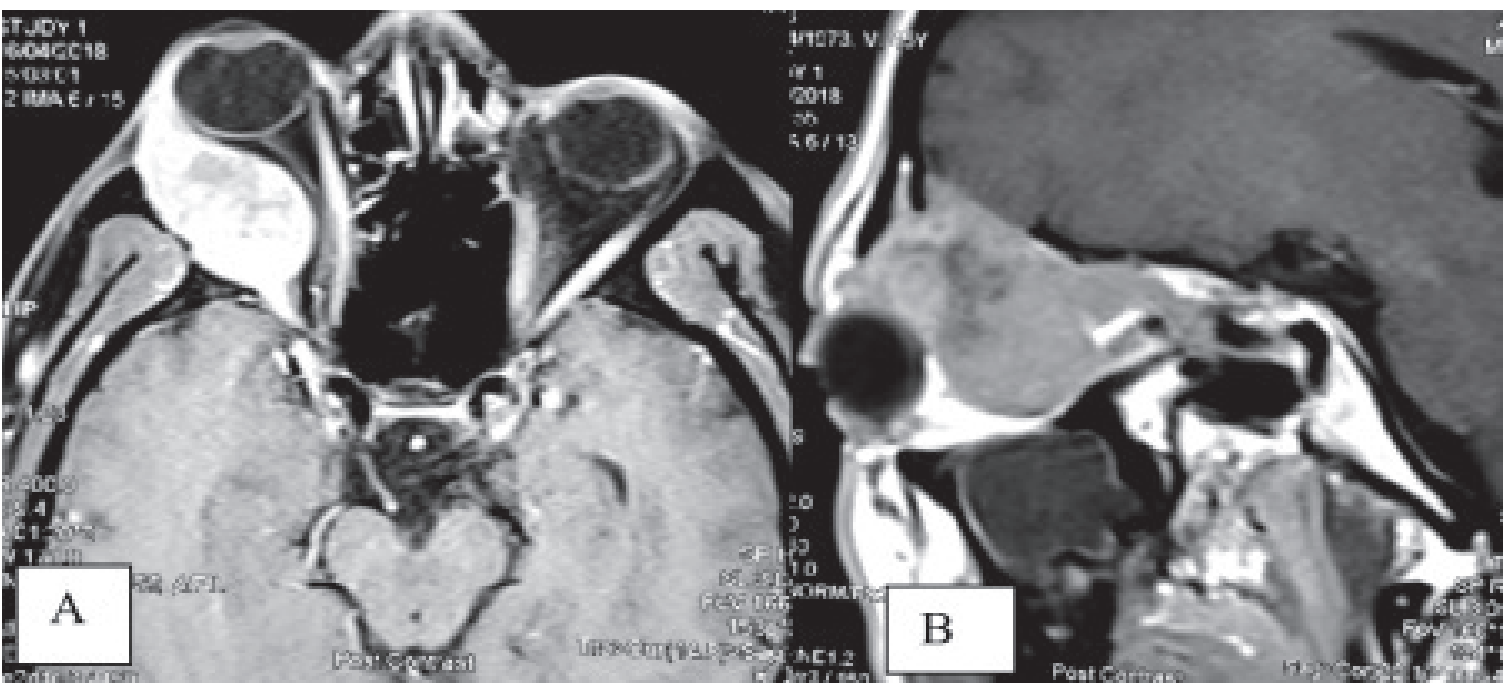

Fig.-3: MRI of brain with contrast- axial $(A)$ and sagittal $(B)$ sections showing T1WI iso- to hypo-intense retrobulbarextraconal lesion, having attachment with sclera and extension towards anterior cranial fossa. After giving contrast, there is presence ofdural tail sign.

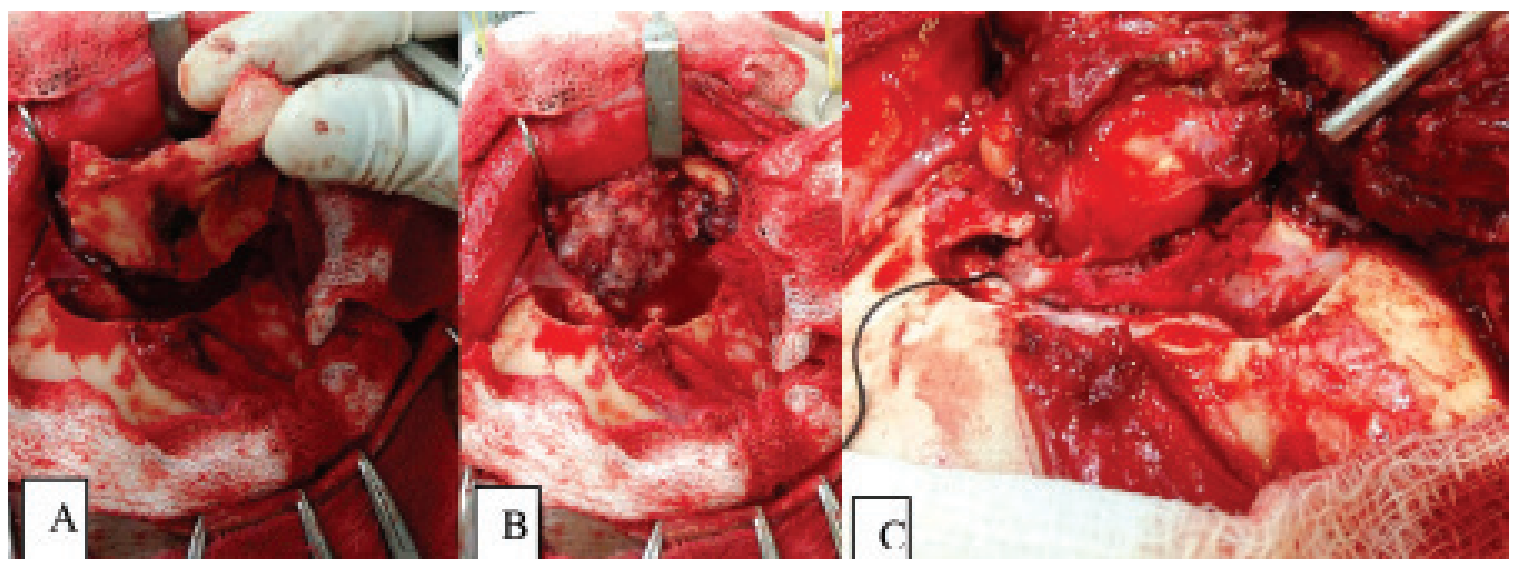

Fig.-4 : Per operative photograph showing- single piece orbito-pterional bone flap (A), greyish red irregular tumor (B), attachment of the tumor with the eyeball (C).

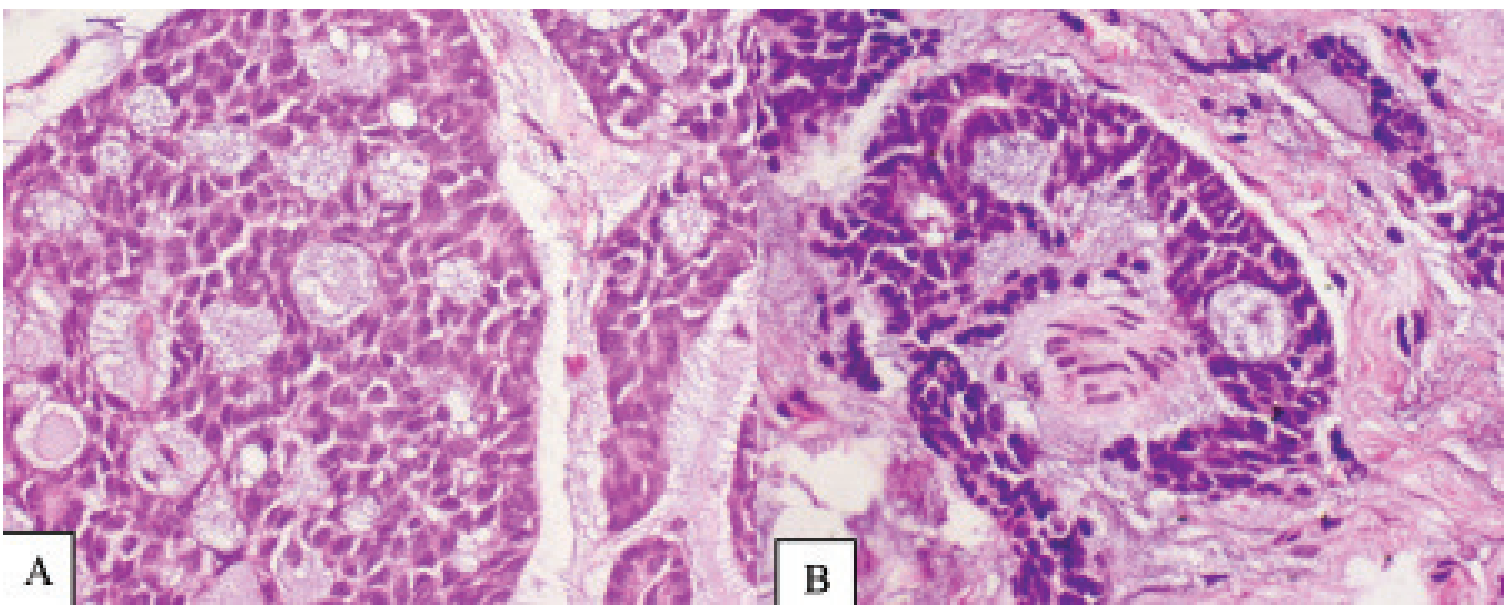

Fig.-5: Adenoid cystic carcinoma showing small tumor cells and cystic spaces (H\&E x400) (A), Adenoid cystic carcinoma showing perineural invasion (H\&E x400) (B). 
nature and extension,the tumor was classified as Stage - T4 according to American Joint Committee on Cancer (AJCC) classification. On histologic analysis there was small tumor cells and cystic spaces with perineural invasion (Figure 5: A,B). Post operatively, proptosis was aggravated with huge congestion and chemosis. However, at $8^{\text {th }}$ POD these features were almost corrected. Visual acuity and status of extraocular muscle movements were same as pre-operative one. The patient was referred for radiation therapy.

\section{Discussion:}

Adenoid cystic carcinoma is slow growing tumor with aggressive clinical behavior. Though rare in overall incidence, it is the most common malignant lacrimal gland tumor; has a peak incidence in the fourth decade $2,6-8$. Most common clinical presentation is facial pain or numbness following invasion to nerve and extraocular muscle ${ }^{1,9-10}$. Distant metastasis through hematogenous route can be found in the lungs, liver, bone, brain, and kidney ${ }^{8}$. Our patient presented at fifth decade with the features of painless, nonpulsatile proptosis with intermittent excessive watering (Figure 1). He had no feature of facial pain. The clinical course is 8 years before the diagnosis, which is longer in comparison to previously reported cases ${ }^{4,5}$.

CT scan and MRI of brain and orbit with contrast are very useful to differentiate between benign and malignant lacrimal gland tumors to determine the extent of tumor invasion and surgical planning. Onpostcontrast sequence of CT scan of the orbits, benign lacrimal gland tumors are usually round,well-defined with no features of invasion, whereas adenoid cystic carcinomas may appear nodular, irregular, with bone erosion and calcification ${ }^{9,11}$. However, MRI is the preferred modality to evaluate the nature of the lesion and relationship with surrounding neurovascular structure, especially for perineural spread and bone invasion $^{12}$. Adenoid cystic carcinomas typically appearisointense on T1Wl and hyperintense on T2WI. After giving contrast, it takes heterogenous enhancement ${ }^{9}$. In our patient, we did both CT scan and MRI for better delineation of tumor extent and surgical planning. On imaging, patient had a retrobulbarextraconal lesion at the area of right lacrimal fossa. Mass had attachment with posterior sclera with medial displacement of optic nerve. There was erosion of orbital plate of frontal bone and extradural extension to anterior cranial fossa through the bony gap (Figure
2: $A, B$; Figure 3: $A, B)$. Based upon the imaging findings, we planned for orbito-pterional craniotomy for removal of tumor.

Histopathological analysis shows four patterns: cribriform, basaloid/solid, sclerosing, and tubular [2]. Among them, cribriform growth is the most common pattern which is characterized by cystlike structures containing accumulations of basophilic, amorphous glycosaminoglycans or eosinophilic, hyalinized basal lamina. On the other hand, basaloid/solid growth is characterizedby a predominance of basaloidmyoepithelial cells. But multiple patterns can be present in the same sample. Different growth patterns havesignificant impact on prognosis. For example, 5 years survival rate of patients with basaloid/solid patterns is $21 \%$ compared with that of $71 \%$ in patients with non-basaloid patterns ${ }^{2,7,13}$. In our reported case, the growth pattern is cribriform pattern with an expectant better prognosis.

There are several treatment options for the management of this kind of aggressive tumor but the initial preferred modality should be surgical removal of tumor with or without orbitectomy2,14-18. If gross total removal could not be achieved due to lack of cleavage plane between tumor and surrounding structures or if there is evidence of bone invasion, then radiotherapy is recommended for better outcome $^{16,19}$. If gross total removal could not be achieved, then patient may also benefit from neoadjuvantchemotherapy ${ }^{9,18-20}$. We achieved gross total removal of tumor with removal of invaded roof and lateral wall of bony orbit. After that,we referred him for adjuvant radiotherapy as there was intracranial extension and bone erosion.

The American Joint Committee on Cancer (AJCC) classification defines T4 stage, if there is involvement of periosteum or bone ${ }^{21}$. Patients with tumors $\geq \mathrm{T} 3$ at presentation exhibit shorter overall survival and time to metastasis ${ }^{6}$. The recurrence rate of adenoid cystic carcinomas is up to $70 \%$ and worse prognosis is associated with neural invasion, basaloid growth pattern and tumor size $>4 \mathrm{~cm}$ at the time of diagnosis ${ }^{6,9}$. According to this, our reported case was staged as T4, which had perineural invasion. However, overall prognosis is poor in this aggressive malignant tumor.

\section{Reference:}

1. Lacrimal Gland Tumor Study Group. An epidemiological survey of lacrimal fossa lesions in Japan: number of patients and their sex ratio by pathological diagnosis. Japanese journal of ophthalmology. 2005 Sep 1;49(5):343-8. 
2. Wright JE, Rose GE, Garner A. Primary malignant neoplasms of the lacrimal gland. British Journal of Ophthalmology. 1992 Jul 1;76(7):401-7.

3. Font RL, Smith SL, Bryan RG. Malignant epithelial tumors of the lacrimal gland: a clinicopathologic study of 21 cases. Archives of Ophthalmology. 1998 May 1;116(5):613-6.

4. Stanford S, Canders CP, Linetsky M, Lai CK, Abemayor E, Kirsch C. Adenoid cystic carcinoma of the lacrimal gland: a case report with a review of the literature. Journal of Medical Imaging and Radiation Sciences. 2014 Sep 1;45(3):323-6.

5. Falcone MM, Tran KD, Tavakoli M, Ortiz DF, Barredo JC, Lee WW. Adenoid cystic carcinoma of the lacrimal gland in a 14-year-old male. Orbit. 2017 Nov 2;36(6):448-51.

6. Ahmad SM, Esmaeli B, Williams M, Nguyen J, Fay A, Woog J, Selvadurai D, Rootman J, Weis E, Selva D, McNab A. American Joint Committee on Cancer classification predicts outcome of patients with lacrimal gland adenoid cystic carcinoma. Ophthalmology. 2009 Jun 1;116(6):1210-5.

7. Bernardini FP, Devoto MH, Croxatto JO. Epithelial tumors of the lacrimal gland: an update. Current opinion in ophthalmology. 2008 Sep 1;19(5):409-13.

8. Esmaeli B, Ahmadi MA, Youssef A, Diba R, Amato M, Myers $\mathrm{JN}$, Kies M, El-Naggar A. Outcomes in patients with adenoid cystic carcinoma of the lacrimal gland. Ophthalmic Plastic \& Reconstructive Surgery. 2004 Jan 1;20(1):22-6.

9. Von Holstein SL, Coupland SE, Briscoe D, Le Tourneau C, Heegaard S. Epithelial tumours of the lacrimal gland: a clinical, histopathological, surgical and oncological survey. Actaophthalmologica. 2013 May 1;91(3):195-206.

10. Seethala RR, Cieply K, Barnes EL, Dacic S. Progressive genetic alterations of adenoid cystic carcinoma with highgrade transformation. Archives of pathology \& laboratory medicine. 2011 Jan;135(1):123-30.

11. Perez DE, Pires FR, Almeida OP, Kowalski LP. Epithelial lacrimal gland tumors: a clinicopathological study of 18 cases. Otolaryngology—Head and Neck Surgery. 2006 Feb;134(2):321-5.
12. Vaidhyanath R, Kirke R, Brown L, Sampath R. Lacrimal fossa lesions: pictorial review of CT and MRI features. Orbit. 2008 Jan 1;27(6):410-8.

13. Gamel JW, Font RL. Adenoid cystic carcinoma of the lacrimal gland: the clinical significance of a basaloid histologic pattern. Human pathology. 1982 Mar 1;13(3): 219-25.

14. Byers RM, Berkeley RG, Luna M, Jesse RH. Combined therapeutic approach to malignant lacrimal gland tumors. American journal of ophthalmology. 1975 Jan 1;79(1): 53-5.

15. Wilson KF, Ward PD, Spector ME, Marentette LJ. Orbitocranial approach for treatment of adenoid cystic carcinoma of the lacrimal gland. Annals of Otology, Rhinology \& Laryngology. 2011 Jun;120(6):397-400.

16. Skinner HD, Garden AS, Rosenthal DI, Ang KK, Morrison WH, Esmaeli B, Pinnix CC, Frank SJ. Outcomes of malignant tumors of the lacrimal apparatus. Cancer. 2011 Jun 15;117(12):2801-10.

17. Brada M, Henk JM. Radiotherapy for lacrimal gland tumours. Radiotherapy and Oncology. 1987 Jul 1;9(3):175-83.

18. David TT, Benedetto P, Dubovy S, Schiffman JC, Feuer WJ. Clinical analysis of the effect of intraarterial cytoreductive chemotherapy in the treatment of lacrimal gland adenoid cystic carcinoma. American journal of ophthalmology. 2006 Jan 1;141(1):44-53.

19. Meel R, Pushker N, Bakhshi S. Adjuvant chemotherapy in lacrimal gland adenoid cystic carcinoma. Pediatric blood \& cancer. 2009 Dec 1;53(6):1163-4.

20. Meldrum ML, David TT, Benedetto P. Neoadjuvantintracarotid chemotherapy for treatment of advanced adenocystic carcinoma of the lacrimal gland. Archives of Ophthalmology. 1998 Mar 1;116(3):315-21.

21. Rootman J, White VA. Changes in the 7th edition of the AJCC TNM classification and recommendations for pathologic analysis of lacrimal gland tumors. Archives of pathology \& laboratory medicine. 2009 Aug;133(8): 1268-71. 